\title{
Double chambered right ventricle in a patient with hypertrophic cardiomyopathy. A unique coexistence
}

\author{
Paweł Tyczyński ${ }^{1}$, Mateusz Śpiewak², Przemysław Chmielewski ${ }^{3}$, Krzysztof Kotliński ${ }^{4}$, Tomasz Deptuch ${ }^{5}$, \\ Adam Witkowski', Piotr Szymański ${ }^{6}$
}

1Department of Interventional Cardiology and Angiology, National Institute of Cardiology, Warszawa, Poland
2Department of Magnetic Resonance Unit, National Institute of Cardiology, Warszawa, Poland
${ }^{3}$ Unit for Screening Studies in Inherited Cardiovascular Diseases, National Institute of Cardiology, Warszawa, Poland
${ }^{4}$ Department of Cardiac Surgery and Transplantology, Institute of Cardiology, Warszawa, Poland
${ }^{5}$ Cardiology Center, Józefów, Poland
${ }^{6}$ Central Clinical Hospital of the Ministry of the Interior and Administration, Centre of Postgraduate Medical Education, Warszawa, Poland

Correspondence to: Piotr Szymański, MD, PhD, Central Clinical Hospital of the Ministry of the Interior and Administration, Centre of Postgraduate Medical Education,

Wołoska 137,

02-507 Warszawa, Poland e-mail: pszymanski@ptkardio.pl Copyright by the Author(s), 2021

Kardiol Pol. 2021;

$79(7-8): 891-892$ DOl: 10.33963/KP.a2021.0023 Received: May 11, 2021

Revision accepted: May 23, 2021

Published online: May 25, 2021
Double chambered right ventricle (DCRV) is a rare pathology $(0.5 \%-2.0 \%$ of all congenital heart defects) and is considered a primarily congenital defect. The right ventricle (RV) is separated into two chambers with low and high pressure (see detailed description elsewhere) [1]. Numerous papers have reported its coexistence with other heart and extra-cardiac anomalies. Nonetheless, only casuistic reports described the coexistence of DCRV among patients with hypertrophic cardiomyopathy (HCM). Said et al. presented the outcomes of surgical repair of DCRV in 61 patients. HCM was diagnosed in four of those patients [2]. Park et al. [3] described an 80-year-old HCM patient with DCRV who experienced recurrent hypotension and chest discomfort during hemodialysis. Yamamoto [4] reported most probably the first case of a 47-years-old DCRV patient with coexisting severe left ventricle outflow tract obstruction (LVOTO). We describe an HCM patient in whom DCRV was diagnosed in adulthood.

A 52-years-old female with previously diagnosed HCM (without LVOTO) and with elevated pulmonary pressure was referred for further assessment. Transthoracic echocardiography (TTE) showed asymmetrical hypertrophy of the interventricular septum ( $29 \mathrm{~mm}$ ), mild tricuspid regurgitation with estimated right ventricular systolic pressure (RVSP) of $77 \mathrm{~mm} \mathrm{Hg}$, and enlarged right atrium $\left(32 \mathrm{~cm}^{2}\right)$. Transesophageal echocardiography and repeated TTE showed additional tissue narrowing the proximal muscular tunnel between the RV inflow tract (RVIT) and RV outflow tract (RVOT) (Figure 1A and 1B).
Cardiac magnetic resonance (CMR) clearly showed hypertrophied moderator band causing RV narrowing at the level of its basal segments (Figure 1E). Right heart catheterization revealed $\mathrm{RV}$ systolic pressure gradient (RVSPG) of $80 \mathrm{~mm} \mathrm{Hg}$ and pulmonary hypertension was excluded. Subsequently, the patient underwent surgical treatment. After opening RVOT, additional muscular tissue was removed and partial excision of the muscular tunnel between RVIT and RVOT and finally RVOT enlargement with a pericardial patch were performed. The postoperative course was complicated by the right pleural effusion requiring thoracentesis. No recurrence of narrowing within RV was visible on repeated TTE during 8 years of follow-up or on CMR done 3.5 years after cardiac surgery. Right ventricular systolic pressure was around $45 \mathrm{~mm} \mathrm{Hg}$ without significant changes.

Double chambered right ventricle is most frequently encountered in infants and children and not in adult patients as in our case. This report highlights the pitfalls of TTE and the necessity of complementary modalities for the proper diagnosis of rare cardiac defects like DCRV. First TTE-based diagnoses were misleading and indicating a high probability of pulmonary hypertension. This was excluded by right heart catheterization (and already changed the treatment strategy). As acknowledged by other authors, TTE may not be satisfactory in the visualization of anomalous RV muscle band [5]. Transesophageal echocardiography and CMR clearly showed the RV anatomy for pre-surgical workup. The presence of SPG within RV among the HCM population is not an infrequent 


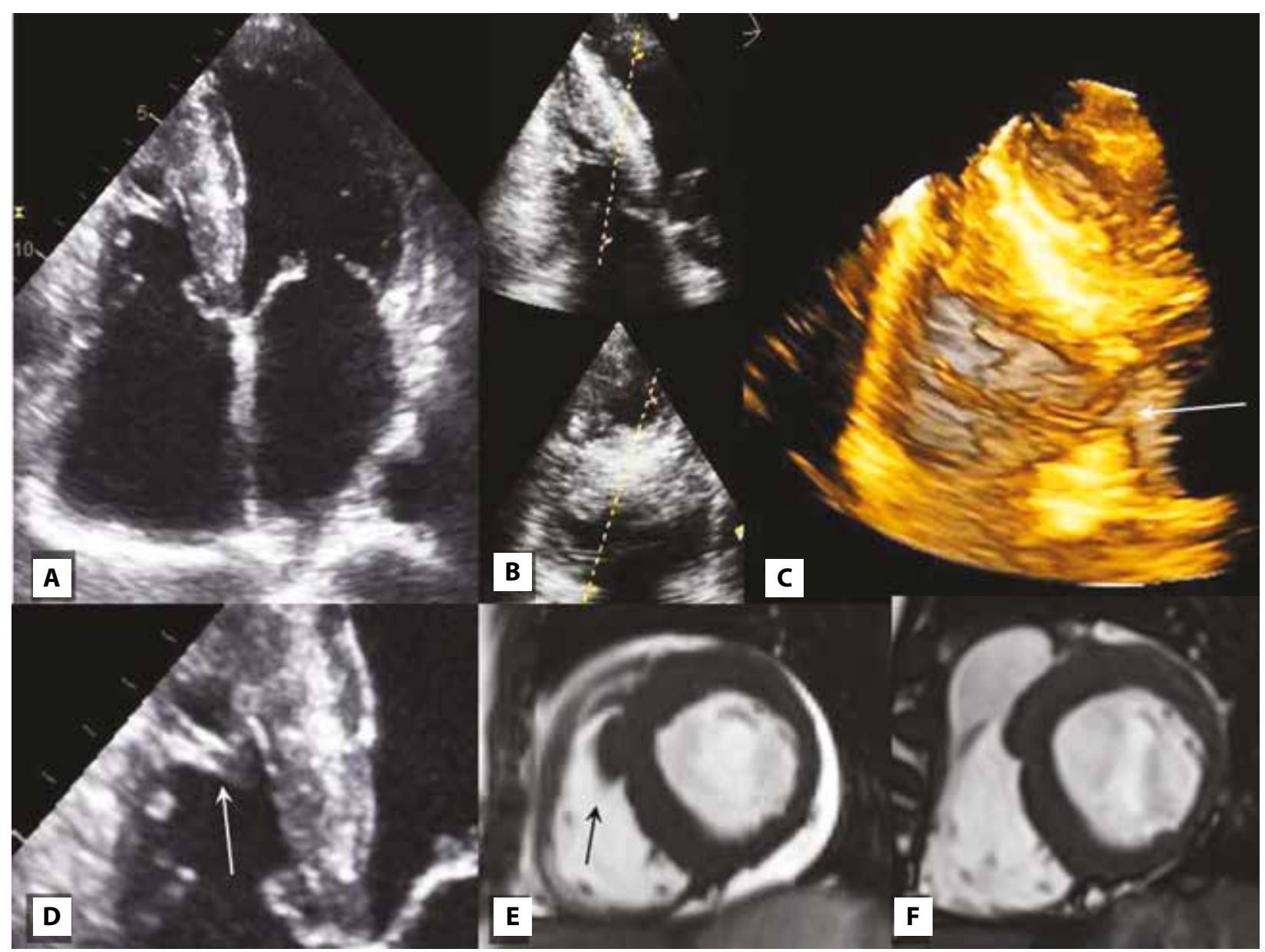

Figure 1. Transthoracic echocardiography. A. Apical 4-chamber view. B. and C. 3D view. The white arrow indicates narrowing between the inflow tract and the outflow tract of the right ventricle. D. Magnification of the image " $A$ ". White arrow indicates hypertrophied moderator band within the right ventricle. E. Cardiac magnetic resonance. Short axis end-diastolic cine image demonstrating hypertrophied moderator band (black arrow). A small amount of pericardial effusion is also seen. F. Post-surgery image after resection of the additional muscular tissue

finding. In a historic HCM population, RVSPG was present in $15 \%$ of patients and ranged between $10 \mathrm{~mm} \mathrm{Hg}$ and $55 \mathrm{~mm} \mathrm{Hg}$, as reported Frank et al. in 1968. Still, it was well below the RVSPG observed in our patient. In summary, it is crucial to distinguish DCRV from other forms of RV obstructions. Of note, DCRV is the only RVOT obstruction classified as sub-infundibular.

\section{Article information}

Conflict of interest: None declared.

Open access: This article is available in open access under Creative Common Attribution-Non-Commercial-No Derivatives 4.0 International (CC BY-NC-ND 4.0) license, allowing to download articles and share them with others as long as they credit the authors and the publisher, but without permission to change them in any way or use them commercially. For commercial use, please contact the journal office at kardiologiapolska@ptkardio.pl.

How to cite: Tyczyński P, Śpiewak M, Chmielewski P, et al. Double chambered right ventricle in a patient with hypertrophic cardiomyopathy. A unique coexistence. Kardiol Pol. 2021; 79(7-8): 891-892, doi: 10.33963/KP.a2021.0023.

\section{REFERENCES}

1. Loukas M, Housman B, Blaak C, et al. Double-chambered right ventricle: a review. Cardiovasc Pathol. 2013; 22(6): 417-423, doi: 10.1016/j.carpath.2013.03.004, indexed in Pubmed: 23701985.

2. Said SM, Burkhart HM, Dearani JA, et al. Outcomes of surgical repair of double-chambered right ventricle. Ann Thorac Surg. 2012;93(1): 197-200, doi: 10.1016/j.athoracsur.2011.08.043, indexed in Pubmed: 22093693.

3. ParkWJ, Son JW, Lee CH, et al. Recurrent hypotension during hemodialysis associated with double chamber right ventricle in hypertrophic cardiomyopathy. Circ J. 2018; 82(12):3104-3105, doi: 10.1253/circj.CJ-17-1361, indexed in Pubmed: 29848883.

4. Yamamoto M, Takashio S, Nakashima N, et al. Double-chambered right ventricle complicated by hypertrophic obstructive cardiomyopathy diagnosed as Noonan syndrome. ESC Heart Fail. 2020; 7(2): 721-726, doi: 10.1002/ehf2.12650, indexed in Pubmed: 32078254.

5. Singh NK, Karn JP, Gupt A, et al. Double chambered right ventricle with ventricular septal defect presenting in adulthood. J Assoc Physicians India. 2011; 59: 451-453, indexed in Pubmed: 22315753. 